\title{
Working Experience, Social Capital and the Performance of Farmers' First Startup
}

\author{
Xianhe Yang \\ School of Management, Tianjin University of Technology, Tianjin 300384, China. \\ 1343854200@qq.com
}

Keywords: farmers' first startup; working experience; social capital; start-up performance.

\begin{abstract}
On the basis of the data of Chinese General Social Survey, the study of the influence of working experience on the performance of farmers' first startup and the role of social capital has been played in the process. The study found that farmers who had a job experience were more productive than those who had no experience.Network scale and network resources are affecting farmers.Public startup performance; Working experience can not only expand the weak relation network,improve the network scale,enrich the network resources,but also can strengthen the use efficiency of social capital.That in turn improves startup performance.In addition,the economic status and entrepreneurial experience of farmers before starting a business also have a significant effect on the startup performance. In the process of entrepreneurship,peasants are confronted with the constraints of human capital and financial capital can improve the return on capital.From the connotation and measurement of social capital,social capital mainly includes network size,network density and network resources. The size of the network owned by peasants,density and resources depend not only on blood and geographical foundations, but also on farmers living and working experience[1]. With the large-scale output of rural labor and non-farm employment,peasant social capital has been expanded and extended on the basis of the original stretching, social networks broke through the traditional blood and geographical constraints. It is mainly reflected that the social network of peasants is typical of Chinese countryside before going out to work. The primary relationship of color is the interwoven "blood and geographical" relationship;After entering the city, gradually expand with "karma and friendship" mainly have rational orientation.Secondary relationships lead to changes in network size and structure.
\end{abstract}

\section{Literature Review}

Social capital comes from social network, which is the sum of social network. Network scale,network density and network resources are three dimensions of social capital.Network scale refers to the number of members with direct contact with individuals. Social capital theory, reflect the individual from the social capital network size range of access to information and resources in the network size,the greater the individual from the social capital in the broader access to information and resources.Network density on behalf of the members of the network connection between the close degree,the more weak relationship between members, the lower the familiar with degrees,network density is smaller,the more information the diversity and novelty,increasing the network efficiency.Weak social relations will have different resources and people of different classes, which will benefit the individual to obtain the necessary social capital in instrumental action[1].The low density social network means the non-redundancy of information.Once it occupies the position of "structure hole" in the low density network,it means that the individual has more resources and information hunting advantage. The network resource is another dimension of social capital,which represents the overall condition of the embedded social resources quality in the network of entrepreneurs, and the high quality network resource means more effective social capital.In the social and economic system in which the distribution of resources and information are not the same and show "pyramid" shape,moving closer to the top with high social status of minority people,the more have most of the high quality resources and information[2]. 
Although the function and function of social capital has attracted great attention in the academic circles, the existing research on the impact of social capital on entrepreneurship is not sufficient. In fact, individuals in the entrepreneurial process, often can obtain the required from the embedded network of social capital, and will it into entrepreneurship resources, help the individual well expand opportunity identification, resource mobilization, business development and a series of entrepreneurial process.Especially for farmer entrepreneurs, social capital plays an irreplaceable role in the establishment, survival and development of first startups [3]. Because of a shortage of farmers' cultural level is low, capital ownership, social capital can not only reduce transaction cost, solve the farmers' human capital and financial capital shortage problem, but also can improve the rate of return on capital, is the important way of improving farmers' entrepreneurship performance.

After entering the city,farmers' network heterogeneity increases, and the category of embedded resources also increases, and the resource acquisition channel is expanded[4].With the formation of new relationship between industry and friendship,the proportion of weak relationship with rich resources and strong heterogeneity in the social capital of migrant workers has been increased,and the network density has become smaller.The higher the probability of the high social class being embedded in the social network of the rural migrant workers, the higher the overall quality of the network resources, and thus the solution of the problem of resource shortage of entrepreneurial farmers.

\section{Data Source and Descriptive Analysis}

This paper USES the 2008 Chinese General Social Survey data. The survey covers most provinces and regions of China, including the work experience of residents, social capital and other information closely related to this article. According to the working conditions and hukou status screen entrepreneurial farmers samples, and by convention adopted davids, yu-li zhang and other scholars point of view, will set up time as a start-up first startup within eight years. After eliminating the missing values,223 samples were selected from 6,000 questionnaires, of which 109 were self-employed and 114 had no working experience.

In low-income phase, two groups of farmers have high density function in low-income phase, two groups of farmers have higher density function, but no working experience entrepreneurship the density function of farmers' income is higher, shows that this kind of entrepreneurial farmers performance on the low side, distribution within the range of low performance. Entered the stage of high income situation after contrast, high density function and returning entrepreneurs continue to each other without distribution stage, indicating a working experience of farmer entrepreneurship performance is higher in high entrepreneurial performance range and distribution [5].

The differences between the two groups of farmers in initial performance, social capital and individual endowment were determined by hypothesis testing. The farmers with the working experience have higher start-up performance and more social capital. In particular,the network scale and network resources of farmers with part-time work experience are relatively high,and the network density is low.In addition, the former economic situation is good,the age is small, education degree.Slightly higher and more male,but no significant difference in entrepreneurial experience.

\section{Research Methods and Results}

The results showed that first,the coefficient of working experience (MW) was significantly positive, and the peasants who had the working experience were better than the peasants who had no such experience.Secondly, the coefficient of network scale (SNN) is significantly positive,indicating that the larger the network size, the more information the entrepreneur is exposed.The coefficient of network resource (SNQ) is also highly significant positive, which means that the more high-level occupation types involved in social network, the more the higher quality network resources can be obtained.The coefficient of network density (SND) is negative but not significant.Thirdly, the interactive symbol of working experience and network scale (MW x SNN) is positive and 
significant,and the working experience can help expand the network of farmers' relations and strengthen the network scale to the start-up performance.Working experience with the network resources (MW x SNQ) interaction is significantly positive,tending to strengthen the influence of the network resources of start-up performance,to increase the high social class groups embedded in the probability of farmers' social networks, the overall quality of the network resources is optimized.The interaction between working experience and network density (MW * SND) is significantly negative, and entrepreneurial farmers with working experience can make full use of the advantages of resource diversity in low density network and benefit from it.

In addition, farmers with entrepreneurial experience (EXP) are significantly better than those who do not have entrepreneurial experience. Before starting a business, the economic situation (PREE) significantly reverses the start-up performance. The lower the economic pressure,the higher the performance level. Gender (SEX) is positively impacting the performance of entrepreneurship, indicating that men's entrepreneurial performance is superior to women's. The entrepreneurial performance of farmers in the east (ARE1) is significantly better than that in the west, and there is no significant difference between the central (ARE2) and western farmers' start-up performance.

\section{Research Conclusions and Policy Implications}

In this paper,the research results show that the farmers with working experience of startup performance is significantly higher than without the experience of farmers, the social capital of network size and network resources significantly affects the startup performance,especially when moving on to phase high performance network resource's influence is greater.Farmers with part-time jobs have larger networks, richer resources,lower density and better use of social capital to improve start-up performance.In addition, with the improvement of sub-loci,the rate of return of social capital has become an important reason for the increase of the performance gap between the two groups of farmers.In addition, the economic situation and entrepreneurial experience before starting a business also significantly affect the startup performance.

The above conclusions have the following implications for improving the startup performance of farmers in China.On the one hand, entrepreneurial farmers should attach importance to the social capital is an important resource allocation substitution mechanism,during the work and in other social activities to strengthen individual network construction,in combination with entrepreneurship targeted building is given priority to with "industry margins and friendship" relationship network,improving the quality of embedded network resources.Network, on the other hand, is the core elements of social capital,the government should optimize the service level,contact for entrepreneurial farmers engaged in financial,scientific research,marketing and other related people, help to entrepreneurial farmers access to high quality valuable information and resources.In addition,the local government and rural credit cooperatives and other financial institutions,social capital can be as soft information is introduced into the evaluation index of the start-up farmers growing priority support has abundant social capital,have working experience, before starting a business economic conditions good farmer's entrepreneurial activity.

\section{References}

[1]. James Coleman.Social Capital in the Creation of Human Capital [J].American Journal of Sociology, 1988: 95-120.

[2]. TA Ostgaard.New Venture Growth and Personal Networks [J].Journal of Business Research, 1996, 36(5):37-50.

[3]. Lin Nan.Social Capital: A Theory of Social Structure and Action [M].New York:Cambridge University Press,2001. 
[4]. Maria Brjesson,Jonas Eliasson,Muriel B Hugosson.The Stockholm Congestion Charges-5 Years on Effects,Acceptability and Lessons Learnt[J].Transport Policy,2012( 20):1-12.

[5]. Bjrn Hrsman,John M Quigley.Political and Public Acceptability of Congestion Pricing: Ldeology and Self-interest[J].Journal of Policy Analysis and Management,2010,29(4):854-874. 